\title{
Avaliação de riscos à saúde e intervenção local associadas ao convívio com cães e gatos, Jardim Paraná, Brasilândia. São Paulo, SP, 2003
}

Assessment of health risks and local intervention associated to living together with dogs and cats, developed at Jardim Parana, district of Brasilandia. São Paulo, SP, Brazil, 2003

Evaluación de riesgos a la salud y intervención local asociadas a la convivencia con perros y gatos en el Jardim Paraná, distrito de Brasilândia. São Paulo, SP, Brasil, 2003

Luciana Hardt Gomes'; Marilene Fernandes de Almeida²; Noêmia Tucunduva Paranhos ${ }^{3}$; Rita de Cássia Garcia ${ }^{4}$; Vânia de Fátima Plaza Nunes ${ }^{5}$, Hildebrando Montenegro Neto ${ }^{6}$; Sônia Maria Sodré Cardoso ${ }^{7}$

Centro de Controle de Zoonoses da Secretaria Municipal da Saúde. São Paulo, SP, Brasil

'Médica Veterinária. Diretora do Centro de Controle de Zoonoses de São Paulo, SP. CRMV-SP 6024

${ }^{2}$ Bióloga. Diretora do Laboratório de Zoonoses e Doenças Transmitidas por Vetores. São Paulo, SP

${ }^{3}$ Médica Veterinária. Assistente Técnica de Direção do Centro de Controle de Zoonoses de São Paulo, SP. CRMV-SP 2842

${ }^{4}$ Médica Veterinária. Assistente Técnica da Agência de Saúde do Estado de São Paulo. CRMV-SP 5653

${ }^{5}$ Médica Veterinária. Prefeitura Municipal de Jundiaí, SP. CRMV-SP 4119

${ }^{6}$ Biólogo. Assistente Técnico de Direção do Centro de Controle de Zoonoses de São Paulo, SP

${ }^{7}$ Médica Veterinária. Centro de Controle de Zoonoses de São Paulo, SP. CRMV-SP 2709 


\section{Resumo}

Objetivos: Realizar diagnóstico situacional das interações entre homem, animal e ambiente; testar modelo de intervenção e controle na população de cães e gatos; sensibilizar a população local para a melhoria da saúde animal e saúde humana. Material e Método: O projeto "Avaliação de riscos à saúde e intervenção local associadas ao convívio com cães e gatos” foi desenvolvido no Jardim Paraná, área de invasão localizada no Distrito da Brasilândia, São Paulo, SP, em 2003, pelo Centro de Controle de Zoonoses do Município de São Paulo. Foram realizados censo animal, vacinações, tratamento de ectoparasitas e endoparasitas, registro geral animal, esterilização de animais, exames sorológicos e de solo e remoção de animais. Resultados: Dos domicílios pesquisados, $47 \%$ tinham animais. Do sangue coletado, 31\% dos cães e 19\% dos gatos foram reagentes para toxoplasmose; $49,1 \%$ das amostras de cães apresentaram anticorpos contra raiva acima de $0,5 \mathrm{UI} / \mathrm{ml} ; 100 \%$ das amostras de solo apresentaram positividade para zoonoses parasitárias. A adesão pela população ao programa foi alta e a solicitação para remoção de animais, baixa. Existe alta taxa de renovação da população de cães e gatos, provavelmente devido às situações econômica, sanitária e social da população humana. Conclusões: Todos os animais apresentaram reatividade a mais de uma doença, indicando que a suscetibilidade associada ao ambiente desfavorável pode, igualmente, expor a população humana a riscos à saúde. Tais riscos podem ser minimizados por meio de ações mais globais envolvendo saneamento do ambiente e promoção da saúde animal.

Palavras-chave: Zoonoses. Planejamento em saúde comunitária. Estratégias locais. Saúde animal. Meio ambiente e saúde pública. Fatores de risco. Homens. Animais. Vínculo homem-animal. Estudos de intervenção. Controle da população. Esterilização reprodutiva. Cães. Gatos.

\section{Introdução}

Os seres humanos convivem com animais há milhares de anos. Essa convivência existe também nas cidades, onde a disponibilidade de água, alimento e abrigo ofertados sem restrição favorece o crescimento da população de diferentes espécies animais como roedores, insetos, pombos, morcegos e animais de estimação.

Avalia-se que a população canina mundial seja de 500 milhões de animais (WANDELER et al. ${ }^{1}, 1993$ ). As populações canina e felina estimadas para a cidade de São Paulo são respectivamente 1.490 .412 e
226.484; ou 1 cão para 7 habitantes e 1 gato para 46 habitantes (PARANHOS, ${ }^{2} 2002$ ).

Em 1965, ocorreram 22 óbitos humanos por raiva - o maior número de que se tem registro e 1.408 focos de raiva canina e felina ${ }^{3}$. Em 1973, a Prefeitura de São Paulo inaugurou o Centro de Controle de Zoonoses (CCZ), inicialmente com as ações de campanha anual de vacinação contra a raiva para cães e gatos, apreensão de animais soltos em vias públicas, observação de cães e gatos envolvidos em agravos a humanos e envio de amostras de animais para diagnóstico. Os animais não resgatados pelos proprietários são submetidos à eutanásia, conforme leis municipais 10.309/87e 
13.131/01, ou enviados para programas de adoção. Com essas atividades, os últimos casos de raiva humana e de cães ocorreram, respectivamente, em 1981 e 1983, mantendo-se o controle da doença no Município, desde então.

Em 1985, o CCZ foi credenciado como "Centro de Referência Nacional para Zoonoses Urbanas" e em 1994 foi designado pela Organização Mundial de Saúde (OMS) como "Centro Colaborador para Treinamento e Pesquisa em Zoonoses Urbanas", enfatizando a relevância dos serviços prestados nos âmbitos nacional e internacional.

De acordo com a OMS, a apreensão sistemática e a eutanásia de cães foram utilizadas em várias partes do mundo em função do desconhecimento sobre a composição e a dinâmica da população canina. Estudos atuais demonstram que a eutanásia é menos efetiva e apresenta custo mais alto que o controle da reprodução animal e de programas educativos para a população $0^{4,5}$.

A retirada de animais de companhia de uma área, sem que se alterem a disponibilidade de abrigo, a água e o alimento, propicia a ocupação desse mesmo espaço por outros indivíduos, muitas vezes suscetíveis à raiva e a outras zoonoses ${ }^{6}$.

O CCZ investiu nos últimos anos na educação da posse responsável de animais de estimação e no controle reprodutivo da população animal, tendo em vista que a superpopulação de animais é questão séria a ser superada. Hoje centenas de animais circulam pelas ruas, sofrendo maus tratos e criando situações de risco à saúde humana e à saúde animal pela transmissão de doenças e agravos.

O projeto proposto pelo CCZ “Avaliação de riscos à saúde e intervenção local associadas ao convívio com cães e gatos" foi desenvolvido em área-piloto, com recursos locais, visando testar modelo diferenciado de remoção de animais, associando outras intervenções para o controle de cães e gatos. O projeto objetivou ainda estudar o potencial zoonótico representado pelo ambiente e pelos animais, caracterizar a população animal e conhecer suas interações com o homem e o meio ambiente, para ações futuras na intervenção junto à comunidade.

\section{Material e Método}

\section{Caracterização da Área}

Definiu-se como área-piloto o Distrito Administrativo (DA) da Brasilândia com alta densidade populacional humana e de cães/gatos, elevado número de solicitações para remoção de cães soltos em vias públicas e de acidentes por mordedura. Em decorrência da extensão territorial do Distrito Sanitário (DS), selecionou-se uma região correspondente à área de

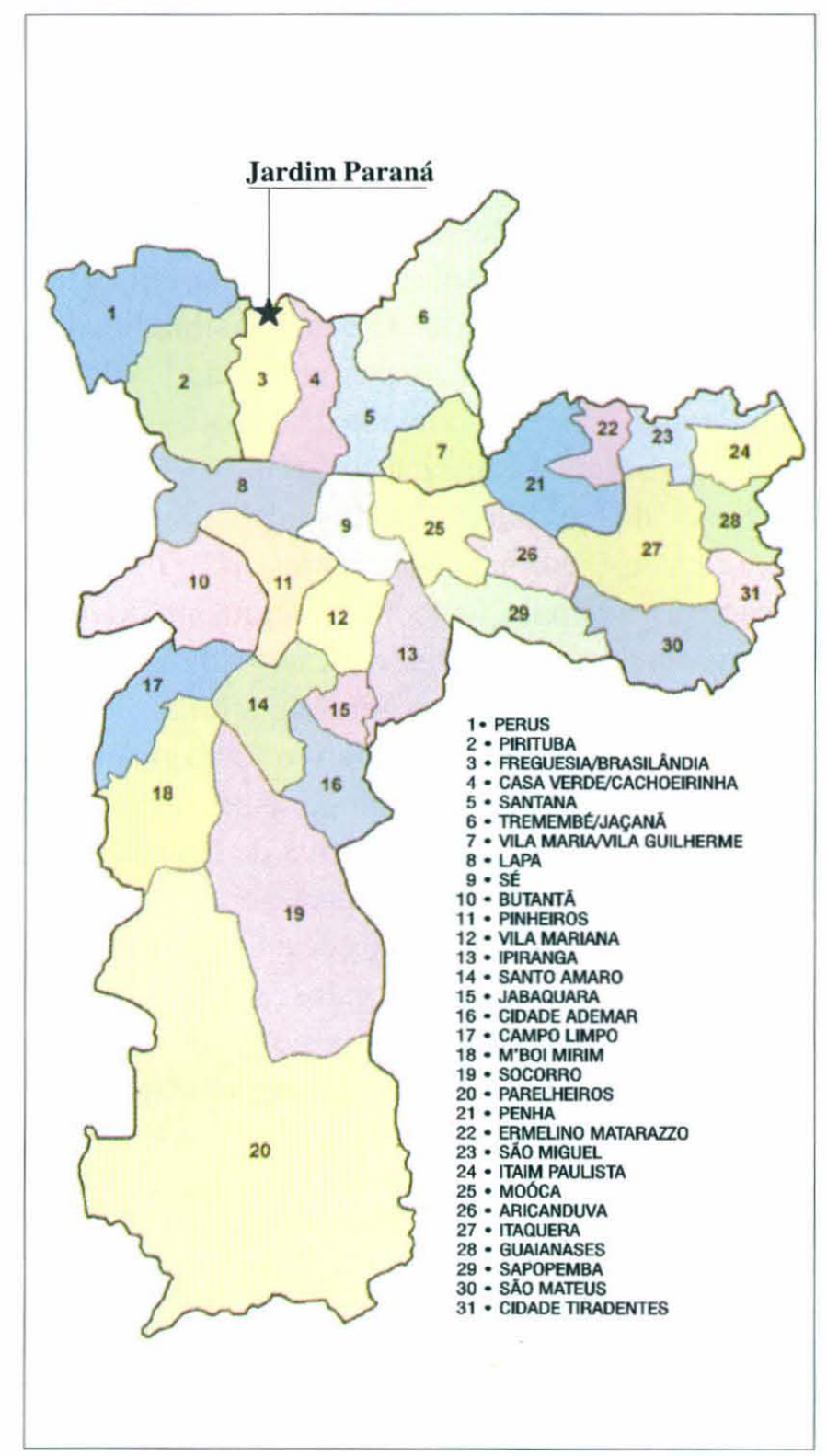

Figura 1 - Mapa do Município de São Paulo com Divisão por Subprefeituras, 2003 
abrangência de uma das Unidades Básicas de Saúde (UBS), elegendo-se a comunidade do Jardim Paraná da Unidade Básica de Saúde (UBS) Vista Alegre, conforme indica a Figura 1.

O Jardim Paraná é área de invasão na Serra da Cantareira, com condições socioeconômicas precárias, constituída de 952 moradias de tijolos/blocos e 418 moradias de madeira. São 1.208 moradias com destinação de esgoto a céu aberto. Conforme dados gerados pelos agentes comunitários do Programa Saúde da Família (PSF), existem 1.390 famílias residindo no local, totalizando 5.175 pessoas.

\section{Ações Desenvolvidas}

O projeto foi desenvolvido pelo $\mathrm{CCZ}$ em parceria com a Supervisão de Vigilância em Saúde (SUVIS) da Freguesia do Ó e da Brasilândia, pela UBS Vista Alegre e por agentes comunitários do Jardim Paraná, com envolvimento dos profissionais do nível local. Houve capacitação da equipe do Programa Saúde da Família (PSF); diagnóstico situacional da área; censo animal (por agentes do PSF); divulgação para a população local; atendimento dos cães e gatos em postos volantes, com serviços de vacinação contra raiva, registro geral do animal (RGA), cadastro para controle reprodutivo (cirurgia gratuita), tratamento de ecto e endoparasitas e coleta de sangue para avaliação sorológica de leptospirose, leishmaniose, toxoplasmose, raiva e brucelose; coleta de solo; remoção autorizada de animais; cirurgias de esterilização dos cães e gatos, subsidiadas por organizações não-governamentais (ONGs) conveniadas com a Prefeitura: Aliança Internacional do Animal, Quintal de São Francisco, Associação Paulista de Amparo aos Animais, Estimação e Clube das Pulgas.

Considerando a dificuldade de transporte dos animais e a distância das clínicas veterinárias na região, optou-se pela realização das cirurgias na própria comunidade. A esterilização foi realizada em 13 dias distribuídos em três semanas nos meses de junho, julho e agosto, seguindo agendamento prévio.

\section{Diagnóstico laboratorial}

As técnicas utilizadas para diagnóstico foram:

\section{Para cães e gatos:}

Sorologia para leishmaniose: imunofluorescência indireta;

- Raiva: cultivo celular-RFFIT (Técnica de inibição de focos de fluorescência rápida) com $0,5 \mathrm{UI} / \mathrm{ml}$ utilizado para humanos, como ponto de corte;

- Toxoplasmose: imunofluorescência indireta.

\section{Para cães:}

- Leptospirose: soroaglutinação microscópica (MAT);

- Isolamento da Leptospira spp: hemoculturas em meio EMJH semi-sólido com suplemento de albumina bovina em dois dias diferentes em 46 amostras coletadas;

- Brucelose: imunodifusão em gel de ágar (anticorpos precipitantes anti Brucella canis).

\section{Para amostras de solo:}

Amostras de 5 diferentes locais do Jardim Paraná, (com alta freqüência de crianças e animais): flutuação em sacarose (densidade 1270), flutuação em dicromato de sódio (densidade 1350), Baermann modificado, sedimentação Ritchie, coloração pela auramina e Ziehl-Nielsen modificado.

\section{Resultados}

\section{Censo}

Na Tabela 1 estão expostos os resultados do censo. 
Tabela 1 - População humana e animal, Jardim Paraná, Brasilândia, São Paulo, SP. Centro de Controle de Zoonoses de São Paulo, 2003

\begin{tabular}{lccc}
\hline \multicolumn{1}{c}{ Descrição } & $\mathrm{N}^{2}$ & $\begin{array}{c}\text { Razão } \\
\text { homem: animal }\end{array}$ & $\begin{array}{c}\text { Idade média } \\
\text { (em anos) }\end{array}$ \\
\hline Famílias & 1.390 & - & - \\
\hline Pessoas & 5.175 & - & - \\
\hline Domicílios pesquisados & 1.215 & - & - \\
\hline Domicílios pesquisados sem animais & 668 & - & - \\
\hline Domicílios pesquisados com animais & 547 & - & 1,67 \\
Domicílios pesquisados com cães & 382 & - & 3,00 \\
\hline Domicílios pesquisados com gatos & 163 & - & - \\
Cães & 553 & $1,54: 1$ & - \\
Gatos & 231 & $1,67: 1$ & - \\
Macho:fêmea (gatos) & - & $22,00: 1$ & - \\
\hline Macho:fêmea (cães) & - & $9,00: 1$ & - \\
\hline Homem:gato & - & - & - \\
\hline Homem:cão & & & - \\
\hline
\end{tabular}

Do total de domicílios pesquisados (1.215) por meio do censo casa-a-casa, a proporção de domicílios com cães ou gatos foi de 45,02\%. Do total de domicílios com animais, os que possuíam cães eram $56,31 \%$; os que possuíam somente gatos; $16,27 \%$ e $13,53 \%$ possuíam cães e gatos.

O número de moradores do Jardim Paraná, segundo dados fornecidos pela UBS Vista Alegre, no período pesquisado (maio e junho de 2003) era de 5.175. A média de pessoas por domicílio foi de 4,26. Dos domicílios pesquisados, a média de habitações com cães foi de 1,45 e a média de cães pelo total de domicílios foi de 0,45 . Em relação aos gatos, as médias foram de 1,42 e 0,19 , respectivamente.

A população canina domiciliada no Jardim $\mathrm{Pa}$ raná foi de 553 animais e a felina, 231 animais; as razões encontradas homem:cão e homem:gato foram
9:1 e 22:1, respectivamente. A razão de cães machos para fêmeas foi de 1,67 e dos gatos machos para fêmeas foi de 1,54. Do total de cães, 2,35\% eram machos esterilizados e 1,99\% eram fêmeas esterilizadas. Entre os gatos, 2,60\% eram machos esterilizados e $2,16 \%$ eram fêmeas. O total de cadelas gestantes ou com filhotes foi de $3,61 \%$ e para as gatas, $3,89 \%$.

A idade média dos cães foi de 3,0 anos e a dos gatos de 1,67 anos. Apenas 6,69\% dos cães e 1,73\% dos gatos possuíam 8 ou mais anos de vida.

A maneira mais freqüente pela qual os animais foram introduzidos no Jardim Paraná foi sob forma de presente, representando $42,22 \%$ para cães e $13,14 \%$ para gatos. Outra forma importante foi a adoção de animais achados nas ruas para ambas as espécies (Tabela 2). 
Tabela 2 - Proporção de animais segundo espécie e origem, Jardim Paraná, São Paulo, SP. Centro de Controle de Zoonoses de São Paulo, 2003

\begin{tabular}{lcc}
\hline Origem & \% Cão & \% Gato \\
\hline Achadona rua & 10,08 & 6,76 \\
\hline Adotado de instituição & 3,57 & 0,00 \\
Comprado & 3,44 & 0,26 \\
Cria própria & 5,74 & 6,12 \\
Outros & 0,77 & 0,64 \\
Presente & 42,22 & 13,14 \\
Sem informação & 4,72 & 2,55 \\
\hline Total & $\mathbf{7 0 , 5 4}$ & $\mathbf{2 9 , 4 6}$ \\
\hline
\end{tabular}

\section{Ações Realizadas}

Foram atendidos nos postos volantes 1.251 animais, $46,16 \%$ provenientes do Jardim Paraná e $53,84 \%$ de bairros vizinhos. Em relação às populações canina e felina do Jardim Paraná levantadas pelo censo (553 cães e 231 gatos), $74,14 \%$ dos cães e $73,16 \%$ dos gatos receberam atendimento dos serviços disponibilizados pelo projeto.
Os animais vacinados contra raiva corresponderam a $94,83 \%$ dos cães atendidos e $91,17 \%$ dos gatos. A cobertura vacinal contra raiva no Jardim Paraná foi de 69,98\% para os cães e 67,10\% para os gatos. Dentre os animais de outras localidades que foram buscar atendimento, 95,16 \% dos cães e $88,54 \%$ dos gatos receberam vacina contra raiva $(\mathrm{Ta}-$ bela 3).

Dos animais atendidos nos postos volantes do Jardim Paraná, 49,11\% dos gatos foram esterilizados pelo projeto, correspondendo à aproximadamente $35,93 \%$ do total da população felina do bairro. Nos bairros vizinhos esse percentual foi ainda maior, perfazendo $81,25 \%$ dos gatos atendidos. Neste caso, não se dispõe de censo o que impossibilita a avaliação do impacto da ação sobre as populações animais.

Em relação aos cães, $16,10 \%$ dos animais atendidos do Jardim Paraná foram esterilizados, o que equivale a $11,93 \%$ da população canina total estudada. Foram encaminhados espontaneamente 12 cães para remoção e eutanásia. Parte desses animais estavam doentes e parte sadia. Esse resultado equivale a 1,24 \% de todos os cães atendidos do Jardim Paraná e imediações.

Tabela 3 - Atendimento aos animais e cobertura vacinal, Jardim Paraná, Brasilândia, São Paulo, SP. Centro de Controle de Zoonoses de São Paulo, 2003

\begin{tabular}{|lll}
\hline \multicolumn{1}{|c}{ Descrição } & No & $\%$ \\
\hline Cães atendidos pelo projeto & 968 & - \\
\hline Gatos atendidos pelo projeto & 283 & - \\
\hline Cães do Jardim Paraná atendidos & 410 & - \\
\hline Gatos do Jardim Paraná atendidos & 169 & - \\
\hline Cães de outros locais atendidos & 558 & 74,14 \\
\hline Gatos de outros locais atendidos & 96 & 73,16 \\
\hline Cães atendidos / população de cães do Jardim Paraná & - \\
\hline Gatos atendidos/população de cães do Jardim Paraná & - \\
\hline Cobertura vacinal de cães do Jardim Paraná & - & 69,98 \\
\hline Cobertura vacinal de gatos do Jardim Paraná & - & 67,10 \\
\hline
\end{tabular}




\section{Exames Laboratoriais}

Todas as cinco amostras de solo coletadas no Jardim Paraná apresentaram positividade para agentes parasitários, como mostram os dados do Quadro 1.

\begin{tabular}{|c|c|c|c|c|c|c|c|c|}
\hline Amostras de terra & 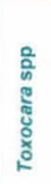 & 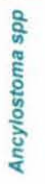 & 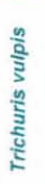 & 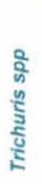 & 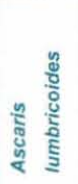 & 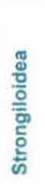 & 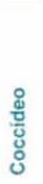 & 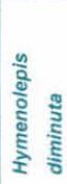 \\
\hline $\begin{array}{l}\text { Pça. Teotônio Villela } \\
\text { (muro) }\end{array}$ & + & + & - & + & + & + & + & - \\
\hline $\begin{array}{l}\text { Pça. Teotônio Villela } \\
\text { (frente casas) }\end{array}$ & + & - & - & - & + & - & + & - \\
\hline $\begin{array}{l}\text { Pça. da Bica } \\
\text { (parte superior) }\end{array}$ & - & + & - & + & + & + & + & - \\
\hline $\begin{array}{l}\text { Pça. da Bica } \\
\text { (parte inferior) }\end{array}$ & + & + & + & + & + & + & + & + \\
\hline Horta comunitánia & - & + & - & + & - & - & + & - \\
\hline
\end{tabular}

Quadro 1 - Resultados parasitológicos de amostras de solo, Jardim Paraná, Brasilândia, São Paulo, SP. Centro de Controle de Zoonoses de São Paulo, 2003

A Figura 2 resume os principais resultados laboratoriais observados nos cães do Jardim Paraná.

As 239 amostras de cães e 96 de gatos foram na-reagentes para leishmaniose. Das 236 amostras caninas analisadas, $49,1 \%$ apresentaram anticorpos rábicos acima de $0,5 \mathrm{UI} / \mathrm{ml}$. Entre as 120 amostras de gatos, $81,7 \%$ apresentaram anticorpos rábicos acima de $0,5 \mathrm{UI} / \mathrm{ml}$.

De 239 amostras de cães analisadas, $41,4 \%$ foram reagentes para anticorpos antileptospira, e 16 animais $(6,7 \%)$ apresentaram título elevado, $>$ ou $=a 800$. Entre os cães sororeagentes para anticorpos antileptospira, 61 animais reagiram para mais de um sorovar, havendo predomínio do sorovar Copenhageni entre as amostras analisadas. Das hemoculturas para leptospiras $100 \%$ foram negativas dentre as 46 amostras coletadas de cães.
A soroprevalência para toxoplasmose observada foi diretamente proporcional à longevidade dos cães e gatos. Chama a atenção que aproximadamente $30 \%$ dos animais da amostra reagiram tanto para leptospirose quanto para toxoplasmose.

Das 239 amostras de cães, 7 (2,92\%) foram reagentes para brucelose.

A Figura 2 resume os principais resultados laboratoriais observados nos cães do Jardim Paraná.

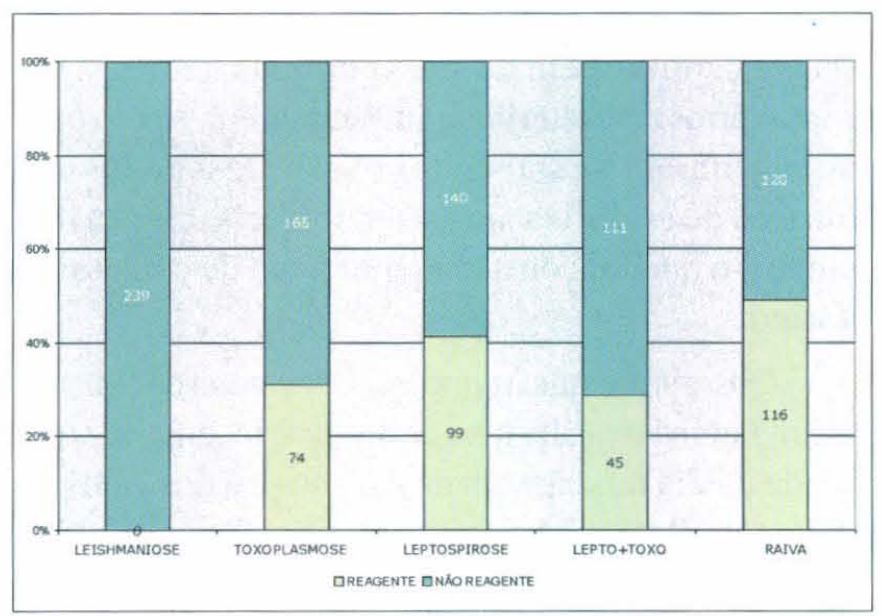

Figura 2 - Resultados de exames laboratoriais em cães. Jardim Paraná, Brasilândia, São Paulo, SP. Centro de Controle de Zoonoses de São Paulo, 2003

\section{Discussão}

A proporção de domicílios com cães ou gatos $(45,02 \%)$ no Jardim Paraná foi semelhante ao observado por Paranhos², 2002 para o Município de São Paulo (43,30\%).

Existem menos cães no Jardim Paraná (1 cão para 9 habitantes) do que o observado por Paranhos ${ }^{2}, 2002$ para o Município de São Paulo (1 cão para 7 habitantes). A proporção de gatos por habitantes é inversa, ou seja, o número de gatos é maior no Jardim Paraná (1 gato para 22 habbitantes) do que no Município (1 gato para 46 habitantes) $)^{2}$.

Do total de cães do Jardim Paraná, 2,35\% eram machos esterilizados e 1,99\% eram fêmeas esterilizadas. No Município de São Paulo, do total de cães pesquisados, $1,31 \%$ eram machos esterilizados e $3,76 \%$ 
eram fêmeas esterilizadas ${ }^{2}$. Entre os gatos do Jardim Paraná, 2,60\% eram machos esterilizados e $2,16 \%$ eram fêmeas esterilizadas; no Município, os valores observados foram $8,6 \%$ e $18,27 \%$ respectivamente ${ }^{2}$.

Durante o desenvolvimento do projeto, os proprietários de gatos, fêmeas e machos, buscaram mais o controle reprodutivo quando comparados com os proprietários de cães. Os proprietários de gatos podem ter mais consciência em relação à necessidade do controle da natalidade devido ao fato de a fêmea dessa espécie procriar mais vezes do que a fêmea da espécie canina, além de se expor mais nas ruas. Os proprietários que esterilizaram seus animais pelo projeto mostraram-se satisfeitos com os resultados das cirurgias de esterilização e a recuperação clínica dos animais, o que foi constatado por meio de contato telefônico.

Observa-se que as populações canina e felina do Jardim Paraná têm alta taxa de renovação, uma vez que a idade média dos cães foi de 3,0 anos e a dos gatos de 1,67 anos. Para o Município de São Paulo, a idade média dos cães foi de 4,41 anos e dos gatos de 2,56 anos (PARANHOS, 2002). A alta taxa de renovação desses animais significa a manutenção de suscetibilidade a doenças infecciosas, incluindo zoonoses, impedindo, dessa maneira, a formação de uma barreira biológica de proteção para o homem e para outros animais.

Houve baixa adesão à remoção e eutanásia dos animais pela população atendida globalmente do Jardim Paraná e imediações, o que equivalente a 1,24 \% de todos os cães atendidos. Embora mereça mais estudos para que se possa aferir tendência contrária à eutanásia por parte da população, Paranhos ${ }^{2}, 2002$, encontrou semelhante resultado; somente $5,76 \%$ da população era favorável à eutanásia.

A adesão à esterilização, ainda que em número bem menor do que a praticada por proprietários de gatos, foi expressiva no caso dos cães, uma vez que acrescentou à população canina esterilizada um número 9,5 vezes maior ao já existente. Tendo em vista as poucas oportunidades de acesso da população local à esterilização de animais, pode-se inferir que houve um progresso comportamental significativo no que tange à propriedade responsável.
A baixa porcentagem de cães com título de anticorpos rábicos acima de $0,5 \mathrm{UI} / \mathrm{ml}(49,1 \%$ para o total dos cães analisados e $31,4 \%$ para os cães menores de 1 ano) pode estar associada à coleta de amostras quase um ano após a última Campanha de Vacinação contra Raiva Animal. Estudos demonstram que a vacina Fuenzalida Palacius, utilizada em campanhas no Brasil, não mantém títulos acima de $0,5 \mathrm{UI} / \mathrm{ml}$ pelo período de um ano e só confere proteção prolongada após três ou mais doses, o que permite a existência de suscetíveis ao vírus entre os animais mais jovens (SALLUM ${ }^{7}, 1999$; ALMEIDA et al. ${ }^{8}, 1997$; LIMA JÚNIOR $\left.{ }^{9}, 1998\right)$.

A porcentagem de gatos com título de anticorpos acima de $0,5 \mathrm{UI} / \mathrm{ml}$ foi alta $(81,7 \%)$ e não aumentou com a idade do animal (81,5\% - até 1 ano; $80,5 \%$ - 1 a 3 anos; 77,7\% - acima de 3 anos). Isso possivelmente se deve ao fato de que os gatos foram vacinados no dia do atendimento nos postos volantes, e o sangue, em decorrência da dificuldade de manejo dos animais, foi colhido após 30 a 40 dias, na data da esterilização.

A baixa porcentagem de cães com título de anticorpos rábicos acima de $0,5 \mathrm{UI} / \mathrm{ml}$ alerta para uma situação de risco. O último caso de raiva em animais domésticos ocorreu no Município de São Paulo em 1983, porém o vírus continua circulando por meio de espécies de morcegos, de diferentes hábitos alimentares. Essa situação reforça a necessidade de utilização de vacinas que promovam imunidade mais duradoura, a exemplo das vacinas de cultivo celular, diminuindo o período de janelas imunológicas e o conseqüente risco de transmissão da doença.

Os gatos, pelas suas características comportamentais e noturnas, representam um risco maior em relação à raiva: têm fácil acesso aos morcegos em seus refúgios, particularmente se eles estiverem doentes. O Jardim Paraná localiza-se próximo à área de mata (Serra da Cantareira), havendo relatos de que animais silvestres circulam na região. Dessa forma, é importante que, no controle da doença dos animais domésticos, estes sejam mantidos adequadamente imunizados contra raiva.

O diagnóstico laboratorial de leishmaniose (100\% de soros de cães e gatos não-reagentes) condiz com a 
situação epidemiológica da doença no Município de São Paulo. Não existe transmissão de leishmaniose visceral na cidade, apenas há notificação esporádica de casos humanos de leishmaniose tegumentar na Serra da Cantareira; ocorrem no Município casos importados de leishmaniose visceral em cães.

A detecção de 99 soros reagentes $(58,6 \%)$ para anticorpos antileptospira em 239 cães provenientes de área periférica do Município de São Paulo sem saneamento básico adequado e com infestação por roedores é um forte indicador da circulação de leptospiras entre esses animais e o meio ambiente, implicando risco potencial de ocorrência de casos humanos de leptospirose. A constatação de 16 animais com título $>$ ou $=$ a 800 é sugestivo de infecção aguda. Os animais que reagiram para mais de um sorovar, principalmente com títulos de 400 , podem ser sugestivos de reações cruzadas entre sorovares, o que ocorre com freqüência em infecções agudas. O predomínio do sorovar Copenhageni, que também tem sido o mais freqüentemente isolado em casos humanos de leptospirose no Estado de São Paulo, sugere a participação de roedores sinantrópicos como fonte comum de contaminação tanto para o homem quanto para o cão.

Como os resultados sorológicos das primeiras amostras indicavam a possibilidade de infecção aguda, foram realizadas hemoculturas para tentar isolar o agente. Das, 46 amostras coletadas, 18 apresentaram problemas durante a coleta do inóculo, o que pode ter prejudicado os resultados. Todas as hemoculturas foram negativas. Possivelmente os animais já estavam fora do período de bacteremia (primeira semana da infecção); também ocorreram contaminações por outros agentes, inibindo o crescimento da leptospira (crescimento lento).

As amostras de solo coletadas no Jardim Paraná apresentaram positividade para agentes de zoonoses parasitárias, dos quais destacam-se o Toxocara spp e o Ancylostoma spp por serem agentes de zoonoses importantes. As áreas comuns (praças e horta comunitárias) estavam contaminadas com agentes parasitários. Esses resultados apresentam-se dentro do esperado, considerando-se as condições ambientais do Jardim Paraná. A região não possui sistema adequado de saneamento e a água é utilizada comunita- riamente para bebida, lavagem de roupas e demais necessidades.

O gato é considerado importante reservatório de toxoplasmose em área urbana, enquanto o cão funciona como sentinela da situação epidemiológica. Como esperado, observa-se que a soroprevalência para toxoplasmose é diretamente proporcional à longevidade, fato associado à maior probabilidade de exposição ao Toxoplasma gondii durante a vida do animal.

A prevalência de anticorpos precipitantes antiBrucella canis $(2,92 \%)$ nas amostras analisadas ocorreu dentro dos limites esperados. Estudos anteriores no Município de São Paulo constataram prevalências de 3,2\% (SANDOVAL $\left.{ }^{10}, 1976\right), 7,0 \%$ (LARSSON ${ }^{11}$, 1981) e $7,5 \%$ (CORTES $\left.{ }^{12}, 1988\right)$. A brucelose canina constitui um problema de saúde pública e os resultados obtidos reforçam a necessidade da educação continuada da população visando ao controle, à domiciliação e à posse responsável de animais de estimação.

Os resultados laboratoriais observados mostraram que os animais apresentaram reatividade para mais de uma doença. Este dado associado à idade média baixa $(64,5 \%$ dos cães e $83,1 \%$ dos gatos com idade até 4 anos) demonstra que a população de animais domésticos sofre forte influência do ambiente desfavorável. Tendo em vista que esses animais funcionam como sentinelas, pode-se aferir que a população humana está exposta, da mesma forma, a riscos que podem ser minimizados com ações mais globais envolvendo saneamento do meio e controle da saúde dos animais.

As ações realizadas no projeto "Avaliação de riscos à saúde e intervenção local associadas ao convívio com cães e gatos" atingiram maior área de abrangência do que a inicialmente planejada. Além do Jardim Paraná, a população dos bairros vizinhos, em situação semelhante de exclusão social, buscou atendimento nos postos volantes e no programa de esterilização.

Sugere-se a expansão desse projeto para outras áreas do município, pelo envolvimento das SUVIS, sempre lembrando da necessidade de adequação às realidades locais. A abordagem utilizada permite que o nível local possa intervir nos problemas que forem sendo identificados, aproveitando a equipe multidisciplinar para 
acompanhar em curto, médio e longo prazos os resultados obtidos.

Deve-se considerar, no desenvolvimento de projetos com a referida abordagem, a necessidade de:

- Planejar ações com diagnóstico situacional, facilitando o desenvolvimento das atividades previstas e a participação da comunidade;

- Trabalhar a posse responsável e os programas de intervenção animal, com agentes comunitários, visando à formação de multiplicadores permanentes;

- Capacitar agentes comunitários para a coleta de dados e ações desenvolvidas;

- Adequar questionários, com dados relevantes para análises estatísticas;

- Banco de dados visando às análises estatística e epidemiológica do projeto;

- Atividades educativas com a comunidade para esclarecer dúvidas e reforçar princípios da posse responsável antes, durante e depois do programa de intervenção;

- Várias datas de esterilização para facilitar o acesso ao trabalhador;

- Contato com proprietários de animais ausentes à esterilização agendada para conhecer os motivos da ausência e corrigir falhas.

\section{Conclusões}

1. Os proprietários de animais da espécie felina procuraram mais o controle reprodutivo do que os da espécie canina. dos cães.

2. A idade média dos gatos foi menor do que a

3. Existe alta taxa de renovação da população de cães e gatos (idades médias baixas).

4. A longevidade do animal foi comprometida pelas situações econômica, sanitária e social da população humana.

5. A procura pela remoção animal foi baixa, correspondendo a $1,24 \%$ de todos os cães atendidos.
6. O percentual registrado de cães com título de anticorpos anti-rábicos acima de $0,5 \mathrm{UI} / \mathrm{ml}$ foi baixo. A vacina Fuenzalida Palacius, usada nas campanhas contra a raiva, não conferiu imunidade por um ano, a não ser em cães maiores de 3 anos.

7. Há necessidade da utilização de vacina contra a raiva animal que promova imunidade mais duradoura.

8. A situação imunológica dos felinos domésticos em relação à raiva deve ser reavaliada em outro projeto no qual a coleta de sangue seja feita antecipadamente à vacinação.

9. As áreas comuns (praças e horta comunitárias) do Jardim Paraná estão contaminadas com agentes parasitológicos, incluindo agentes de zoonoses graves como Toxocara spp e Ancylostoma spp.

10. Há risco potencial de ocorrência de casos humanos de leptospirose, indicado pela alta porcentagem de cães $(41,4 \%)$ com anticorpos anti-leptospira (cão sentinela).

11. Constatou-se baixo índice de animais já esterilizados.

12. Considerou-se alta a adesão da população ao programa de esterilização oferecido.

13. A proporção de domicílios com cães ou gatos é considerada alta.

14. Em relação à população humana, a proporção de cães corresponde ao esperado, enquanto a de gatos supera os níveis do Município.

15. Os animais freqüentemente apresentaram reatividade a mais de uma doença, o que indica sua suscetibilidade ao ambiente desfavorável.

16. A população humana igualmente está exposta a riscos (animal = sentinela) que podem ser minimizados com ações mais globais envolvendo saneamento do meio e controle da saúde dos animais.

17. Houve grande receptividade da população local ao projeto.

18. Há necessidade de projetos de educação continuada da população visando ao controle, à domiciliação e à posse responsável dos animais. 


\section{Abstract}

Objective: To carry out a situational diagnosis of interactions among man, animal and environment, to test intervention and control model in dogs and cats and to make local population aware in order to improve human and animal health. Material and Method: The project "Evaluation of risks to the health and local intervention associated to living together with dogs and cats" was carried out in the area invaded in Jardim Paraná, District of Brasilândia, São Paulo city, Brasil, in 2003 by the Center of Zoonosis Control of the São Paulo Municipality. Animal census, vaccinations, treatment of ectoparasitosis and endoparasitosis, animal register, animal sterilization, serological and soil examinations and removal of animals was carried through. Forty seven percent (47\%) out of searched households had animals. Results: Of the collected serum, $31 \%$ of dogs and $19 \%$ of the cats reacted for toxoplasmosis; $49.1 \%$ of the samples of dogs presented antibodies against rabies above 0,5UI/ml and $100 \%$ of the soil samples tested positive for parasitic zoonosis. Population adhesion to program was high and request for animal removal, low. High rate of renewal among the population of dogs and cats, probably due to economic, sanitary and social situation of the human population. Conclusions: All the animals presented reactivity to more than one illness, indicating the susceptibility associated to the unfavorable environment that also exposes human population to health risks, that can be minimized through more global actions involving sanitation of the environment and promotion of animal health.

Keywords: Zoonoses. Community health. Local planning. Animal health. Environment. Risk factors. Human. Animal. Interactions. Intervention. Population control. Sterilization. Dogs. Cats.

\section{Resumen}

Objetivo: Realizar el diagnóstico situacional de las interacciones entre el hombre, el animal y el ambiente, testar modelo de intervención y control en la población de canes y gatos y sensibilizar la población local para la mejora de la salud animal y humana. Material y Método: El proyecto "Evaluación de riesgos a la salud e intervención local asociados a la convivencia con perros y gatos" ha sido desarrollado en el Jardim Paraná, área de invasión localizada en el Distrito de Brasilândia, São Paulo, SP, Brasil, en 2003, por el Centro de Control de Zoonosis del Municipio de São Paulo. Se realizó un censo animal, aplicación de vacunas, tratamiento de ectoparásitos y endoparásitos, registro general animal, esterilización de animales, exámenes suerológicos y del suelo, y remoción de animales. Resultados: De los domicilios investigados, el $47 \%$ tenía animales. De la sangre recogida, el $31 \%$ de los canes y el 19\% de los gatos presentaron reacción a la toxoplasmosis $49,1 \%$ de las muestras de canes presentaban anticuerpos contra la rabia superior a 0,5 UI/ml y el 100\% de las muestras de suelo presentaron resultados positivos para zoonosis parasitarias. La adhesión de la población al programa fue grande y pocas la solicitudes para la remoción de animales. Existe una alta tasa de renovación de la población de canes y gatos, probablemente debido a la situación económica, sanitaria y social de la población humana. Conclusiones: Todos los animales presentaron reacción a más de una enfermedad, lo que indica una susceptibilidad asociada al ambiente desfavorable que, también, expone la población humana a riesgos para su salud; que se pueden minimizar a través de acciones más globales abarcando saneamiento del ambiente y promoción de la salud animal.

Palabras-clave: Zoonosis. Planificación en salud comunitaria. Estrategias locales. Salud animal. Medio ambiente y salud publica. Factores de riesgo. Hombres. Animales. Vínculo ser humano-animal. Estudios de intervención. Regulación de la población. Esterilización reproductiva. Perros. Gatos. 


\section{Referências}

1. WANDELLER, A. I. et al. The ecology of dogs and canine rabies: a selective review. Revue Scientifique et Techinique de l'Office des Epizooties, v. 12, p. 51-71, 1993.

2. PARANHOS, N. T. Estudo das populações canina e felina em domicílios do Município de São Paulo. 2002. 83 p. Dissertação (Mestrado)-Faculdade de Saúde Pública da Universidade de São Paulo, São Paulo, 2002.

3. BOLETIM INFORMATIVO DO CENTRO DE CONTROLE DE ZOONOSES. São Paulo, Centro de Controle de Zoonoses, v. 3, n. 12, 1980.

4. WORLD HELTH ORGANIZATION. Guias para el manejo de la población canina. Genebra: WHO, 1990. $128 \mathrm{p}$.

5. WORLD HEALTH ORGANIZATION. Who Expert Committee on Rabies. 8. report. Geneve: WHO, 1992. 87 p. (Technical report series, n. 824).

6. REUNIÓN DE EXPERTOS DE WSPA/OPS EN TENENCIA RESPONSABLE DE MASCOTAS Y CONTROL DE POBLACIÓN DE PERROS, 2003, Rio de Janeiro, RJ, Brasil. London: World Society for the Protection of Animals, 2003.

7. SAlluM, P. C. Avaliação da prevalência de anticorpos antivírus rábico em amostras de cães errantes do Município de São Paulo. 1999.
69 p. Dissertação (Mestrado)-Faculdade de Saúde Pública da Universidade de São Paulo, São Paulo, 1999.

8. ALMEIDA M.F. et al. Resposta imune humoral de cães à vacina inativada de cérebro de camundongos lactentes, utilizada nas campanhas antirábicas no Brasil. Revista de Saúde Pública, v. 31, p. 502-507, 1997.

9. LIMA JÚNIOR, A. D. Avaliação da dinâmica da raiva canina em Recife através de um modelo matemático determinístico. In: SEMINÁRIO NACIONAL DE ZOONOSES E ANIMAIS PEÇONHENTOS, 3., 1998, Guarapari, ES, Brasil. Apresentação oral.

10. SANDOVAL, L. A. et al. Incidência da brucelose canina na cidade de São Paulo. Biológico, São Paulo, v. 42, p.128-132, 1976.

11. LARSSON, M. H. M. A. et al. Canine brucellosis in São Paulo: serologic survey of kennel and stray dogs. International Journal of Zoonosis, v. 8, p. 85-90,1981.

12. CORTES, V. A. et al. Reações sorológicas para Brucella canis em cães errantes capturados nas proximidades dos parques públicos, reservas florestais e em áreas periféricas do Município de São Paulo, Brasil. Revista da Faculdade de Medicina Veterinária e Zootecnia da Universidade de São Paulo, v. 25, p. 101-107, 1988. 